\title{
Lead Citrate Staining Method
}

National Cancer Institute

\section{Source}

National Cancer Institute. Lead Citrate Staining Method. NCI Thesaurus. Code C92301.

A microscopy staining method that utilizes lead citrate, a mixture of lead nitrate and sodium citrate, and has applications for electron microscopy staining. 